\title{
CONTRol Mobile Robot With Hybrid DRIVE
}

\author{
Ilyukhin Yu. V., Tatarintseva A. V.
}
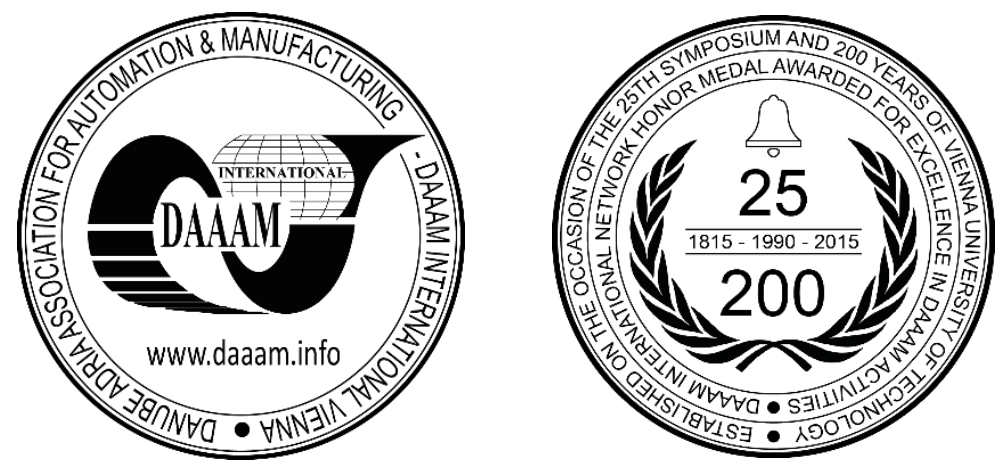

This Publication has to be referred as: Ilyukhin, Y[ury] \& Tatarintseva, A[lexandra] (2016). Control Mobile Robot With Hybrid Drive, Proceedings of the 27th DAAAM International Symposium, pp.0405-0416, B. Katalinic (Ed.), Published by DAAAM International, ISBN 978-3-902734-08-2, ISSN 1726-9679, Vienna, Austria DOI: $10.2507 / 27$ th.daaam.proceedings.060

\begin{abstract}
In the paper we obtained the mathematical model and the organization of automatic traffic control of transport mobile robots with hybrid drives. The hybrid drive is a mechatronic system which consists of an internal combustion engine, an electric torque drive and robot control device. When you build a algorithms and structures of control system of robot with hybrid drive, is taken into account the non-linearity of the characteristics of the hybrid drive, processes of energy recuperation, requirements to dynamic properties of the robot and the efficient using of energy resources. The results of theoretical research supported by the results of computer simulation, which confirmed the effectiveness of the structure and the control system algorithms for the robot motion on different types of path segments.
\end{abstract}

Keywords: mobile robot; motion control; mechatronic system; hybrid drive; internal combustion engine; electric torque drive; computer simulation.

\section{Introduction}

A lot of research is dedicated to the development of autonomous mobile robots, which are necessary to replace human under the difficult operating conditions [1]. Therefore, automatically functioning transport robots are allocated among the mobile robots. They are intended for the delivery of goods over long distances on the condition of their movement, including over rough terrain with the speed varying over a wide range depending on the prevailing situation controlled by robot. Therefore, modern mobile robots must meet the requirements of high rough-terrain performance and intense dynamics and have a great resource of motion with cost-effective use of energy resources. Currently the most common mobile robots have electric drive and controlled motion by a human operator, as a rule, these types of robots don't have the required resource of motions and not able to independently decide on the choice of the speed and operators have to quickly make decisions to control the mobile robot in a changing environment. [2]. Autonomous mobile robots [3-4] equipped with hybrid drives are largely comply the above-formulated requirements. The hybrid drives of mobile robots are mechatronic systems and consist of internal combustion engine (ICE), torque electric drive (TED) and computer control device [5]. It is necessary to develop structures and algorithms for effective use of a hybrid drive for controlling the movement of the robot. It is important to achieve coordinated work of ICE and TED automatically taking into account the non-linearity characteristics of the hybrid drive components and features of energy recuperation processes. Therefore, the task of motion control of mobile robots, equipped with mechatronic hybrid drives is one of the urgent tasks in the field of robotics. 
To a certain extent, this problem is similar to the problem that has been solving in the automotive industry, where everything is increasingly used hybrid propulsion. One of the typical examples of the successful application of the hybrid drive is the car Toyota Prius [6-8]. The difficulty of solving the problem, typical of mobile robotics is due to the need for an autonomous operation of the robot, where the control system on their own, without the involvement of a human operator makes a decision about the most rational way to use features of the hybrid drive for the realization of the desired mode of movement of transport mobile robot.

The paper presents solution to the problem of the control movement of mobile robot with a hybrid drive, which includes a definition of robot structure with the considered type of drive, the formation of its mathematical model, the development of rules and automatic control algorithms in different driving modes, including taking into account energy recuperation processes.

\section{The structure of mobile robot with hybrid drive}

We consider the mobile robot with four wheels, and two front wheels are leading. These wheels are driven by a parallel hybrid type [9]. The mobile robot with hybrid drive has a structure (fig.1) that built in accordance with the principles and methods of mechatronics [10-12]. The main components of the robot are a robot control device, mechatronic power unit and the moving parts of the robot (the robot mechanism) as a control object.

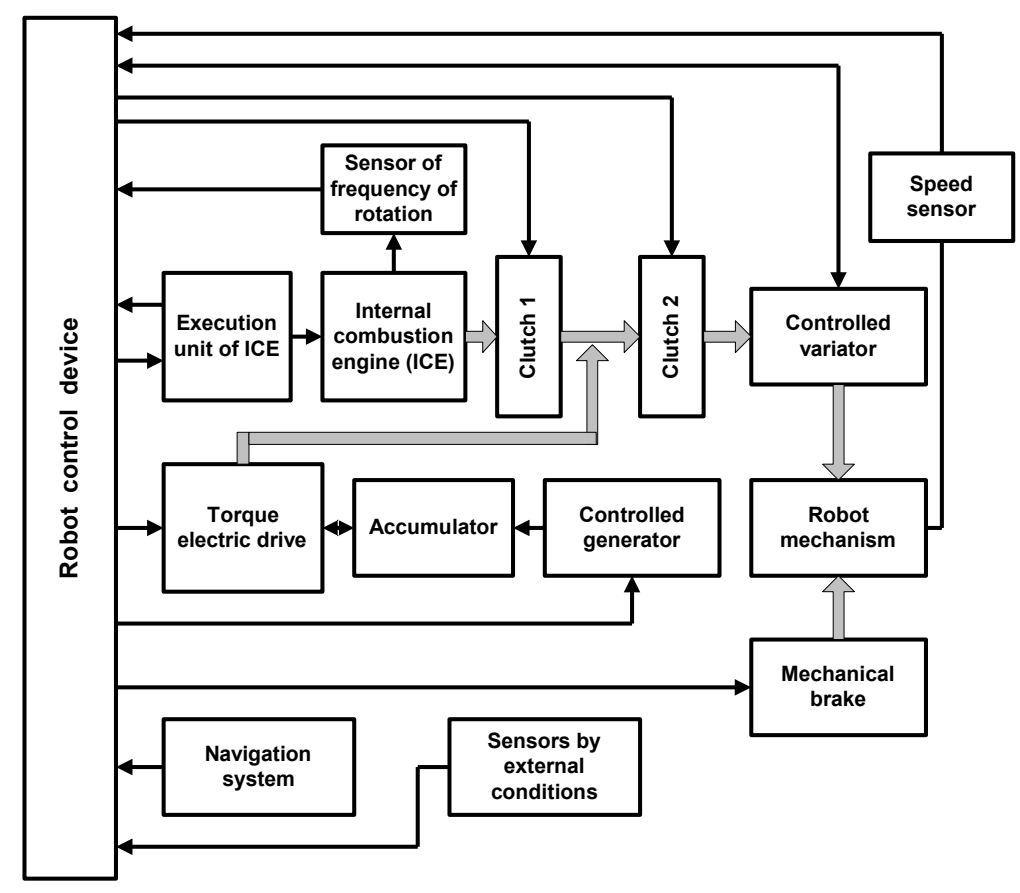

Fig. 1 The structural scheme of mobile robot with hybrid drive

The composition of mechatronic power unit [5] consists of the petrol ICE with executive unit to control ICE, TED, two controllable clutches, controlled gearbox (controlled variator), accumulator, sensor of frequency of rotation ICE, the mechanical brake and controlled generator. Torque electric drive (TED) is built on the basis of the electric motor. So TED is high-speed servo system that is capable of high fidelity reproduction of the torque on the motor shaft.

All of the processes occurring in the robot and its hybrid drive, obey the signals issued by the robot control device. It makes decisions based on data from the speed sensor of the robot, a navigation system and sensors by external conditions. Mobile robot with mechatronic hybrid drive can operate in different modes, and its mechatronic hybrid drive should have a high flexibility in implementing the required torque of the forces. Robot control system can use opportunities the ICE only or separately operated the TED, and can implement a joint coordinated operation of the ICE and the TED.

In this case it is possible to achieve improvement of dynamics during acceleration or deceleration of the robot, as well as improving the energy performance of drive unit, which has a positive effect on the duration of work the robot to the next refueling. Possibility of the ICE and the TED work both separately and jointly provided by using in the hybrid drive two controllable clutches. The main modes of operation of the autonomous mobile robot with a hybrid drive are the movement of the maximum dynamics, the movement at a low speed and energy recuperation mode. In the mode with maximum dynamics, for example, when driving on the rise, mechatronic hybrid drive should cultivate a big torque and create a big acceleration value. In this case, as a rule, the TED helps the ICE, increasing to the required level of the total torque. The intensity of deceleration is also increased, because the TED can create a significant braking torque. In the driving mode with a low speed of the ICE can't operate stably because desired engine speed can be less than the idle 
speed. Therefore, the robot movement is carried out at the expense of TED. The feature of this mode is that the propulsion system of the robot does not create excessive noise.

A limited number of energy resources makes attentive to the choice of control algorithms. Availability of the TED allows effectively replenish the loss of energy in the accumulator. In control recuperation mode, the TED generates a braking torque overcome by the ICE. This ensures replenishment of electric energy in the accumulator. It should be noted, if the robot moves along the terrain, it can be alternation phases summation the ICE and the TED torques. When robot moves on the rise the accumulator electric energy is consumed by the electric drive. Charge of the accumulator is as a result of recuperation energy of the robot on the descent. This increases the energy efficiency of mobile robot and increases its resource of motion. However, in some modes controlled generator can be used for forcible charging. In this case control algorithms should provide control over the degree of charge of the accumulator and its current limit charge.

\section{Mathematical model of mobile robot with hybrid drive as a control object}

Mathematical model of the mobile robot with a hybrid drive, which is the object of control, includes descriptions of interacting components, such as the mechanical part mobile robot (robot mechanism), the ICE and the TED. Torques produced by the ICE and the TED constitute resultant torque $M_{\Sigma}$. Transmission of the robot consists of variator with gear ratio $k_{V A R}$ and the main transmission ratio $k_{M T}$. Translational motion of the mechanical part of mobile robot with a hybrid drive can be described by the following differential equations:

$$
\begin{aligned}
& \frac{d V}{d t}=m_{\Sigma}^{-1}\left(F_{F H D}-F_{M R F}\right), \\
& \frac{d x}{d t}=V,
\end{aligned}
$$

where $V$ and $x$ - speed and movement of the robot accordingly; $F_{F H D}$ - force produced by a hybrid drive; $F_{M R F}-$ motion resistance force; $m_{\Sigma}$ - the equivalent weight of the moving parts of the robot, when

$$
\begin{aligned}
& m_{\Sigma}=m_{R O B}+R_{W}^{-2}\left(4 J_{W}+J_{F F}\right)+R_{W}^{-2}\left(k_{M T} k_{V A R}\right)^{2} J_{R T} \\
& F_{F H D}=M_{\Sigma} k_{M T} k_{V A R} R_{W}^{-1} \\
& F_{M R F}=F_{M R F . I C E}+F_{R F}+F_{F F}+F_{A R}+F_{B R}
\end{aligned}
$$

where $m_{R O B}$ - robot weight; $R_{W}$ - wheel radius; $J_{W}$ - moment of inertia of the wheel; $J_{F F}-$ moment of inertia of the transmission relative to the axis of rotation; $J_{R T}$ - the total moment of inertia of the rotating parts the ICE and the TED; $F_{M R F . I C E}$ - the force, due to the moment of resistance forces in the ICE; $F_{R F}$ - the rolling force, which depends upon the weight and the surface inclination angle at which the robot is located, in relation to the horizontal plane; $F_{F F}-$ the resulting friction force; $F_{A R}$ - the force of aerodynamic resistance of the robot motion; $F_{B R}$ - resistance force caused by brake operation, if they are involved.

$$
F_{M R F . I C E}=M_{M R . I C E} n k_{M T} k_{V A R} R_{W}^{-1}
$$

where $M_{M R . I C E}$ - resistance moment of the ICE; $n$-control parameter equal to 1 if the ICE is connected via the clutch, and equal to 0 if the ICE is disconnected via the clutch.

$$
F_{C K}=m_{P O B} g \sin \alpha
$$

where $g$-acceleration of gravity; $\alpha$ - angle of inclination of the surface on which robot is in relation to a horizontal plane.

The required value of the variator transmission ratio $k_{V A R}$ is set as a function of its desired value $k_{V A R . D}$ by variator regulation subsystem. This subsystem is dynamic, and its properties are characterized by the equation

$$
T_{V A R} \frac{d k_{V A R}}{d t}=k_{V A R . D}-k_{V A R},
$$

where $T_{V A R}$ - the time constant of the variator drive model (this model is given in the form of an aperiodic link).

Mathematical model of the ICE is characterized by nonlinear dependence, which in most cases detected in the analysis of experimental data [13-15]. As a result of analysis of experimental data for the type of internal combustion engine ZMZ- 
40524, $98 \mathrm{~kW}$ [16] using the least squares method, we've obtained an analytical dependence torque on the shaft of the internal combustion engine of the average in one revolution of the crankshaft $M_{I C E}$ and the angular velocity of the crankshaft $\Omega_{I C E}$ and the control action $h$ (the degree of opening of the valve feeding the working mixture). This dependence has the form

$$
M_{I C E}=M_{0} f_{1}\left(\Omega_{I C E}\right) f_{2}\left(\Omega_{I C E}, h\right)+M_{1},
$$

where $h$ can change from 0 to 1 ;

$$
\begin{aligned}
& f_{1}\left(\Omega_{I C E}\right)=\lg \left(k_{1} \Omega_{I C E}+\Omega_{0}\right) \\
& f_{2}\left(\Omega_{I C E}, h\right)=1-k_{2} \exp \left[\left(h_{0}-h\right) b_{1}\left(k_{3} \Omega_{I C E}+b_{2}\right)^{-1}\right]
\end{aligned}
$$

and $M_{0}=37,75 \mathrm{Nm} ; M_{1}=100 \mathrm{Nm} ; k_{1}=1,25 \mathrm{~s} / \mathrm{rad} ; \Omega_{0}=0,0473 \mathrm{rad} / \mathrm{s} ; k_{2}=2,79 ; h_{0}=0,015 ; b_{1}=44,9 ; k_{3}=$ $0,0131 \mathrm{~s} / \mathrm{rad} ; b_{2}=1,07$. The control action $h$ is formed by the control device of ICE depending on its input control signal $U_{C}$. It is described by an aperiodic link with the gain $k_{C D}$ and time constant $T_{C D}$.

The ratio of the angular speed $\Omega_{I C E}$ of the crankshaft to robot speed of the longitudinal movement is given by the equation

$$
\Omega_{I C E}=V k_{M T} k_{V A R} R_{W}^{-1}
$$

The analysis showed that the proposed form of the dependence of the torque of the ICE from $\Omega_{I C E}$ and $h$ is valid for any type of ICE. Therefore, it can be used to describe a hybrid drive of mobile robot. The comparison data obtained via the reduced formulas with experimental data determined that the relative error calculation torque of the ICE is in the range of $5 \ldots 20 \%$ for different types of engines. This demonstrates the suitability of the obtained dependence for the analysis of the properties of the mechatronic hybrid drive of mobile robot.

We consider the torque electric drive (TED) built on the basis of a DC motor. The basis of the TED forms a dynamic drive system, closed current loop the current PI controller and configured to the technical optimum. In considering such a drive system in a first approximation, we can neglect the influence of the motor velocity to the motor current. Then the mathematical model of the system can be described by equation

$$
\frac{d^{2} i_{T E D}}{d t^{2}}+a_{2} \frac{d i_{T E D}}{d t}=a_{1}\left(i_{T E D . R}-i_{T E D}\right)
$$

where $i_{T E D}$ and $i_{T E D . R}$ - actual and required current of the TED accordingly; $a_{1}$ and $a_{2}$ - coefficients, values when tuned to technical optimum depends on cutoff frequency $\omega_{C T}$ of open loop system of the TED and determined by the formulas $a_{1}=2 \omega_{C T}^{2}, a_{2}=2 \omega_{C T}$.

It should be noted that the TED is better to build as closed torque loop servo system. Her straight chain includes seriesconnected controller and the drive system considered above. Considering that this drive system is static, it is proposed to use an integrated controller to increase the dynamic precision torque control of the TED.

\section{The approach to the construction of motion control systems of robots with hybrid drives}

The control system of movement mobile robot (fig.2) is designed to automatically control the speed of the mobile robot. The actual speed $V$ is determined at the input signal $U_{V}$ carrying information about the desired speed $V_{R}$. This system is dynamic and closed by a longitudinal movement of the robot speed. The desired speed $V_{R}$ of movement of the robot is formed by a system of a higher rank in the planning of the route of movement and during the subsequent operational adjustments taking into account the detected obstacles, the state of the road and a number of other factors that affect the speed of traffic on the selected route. Established impact $U_{V}$ undergoes an additional adjustment to the calculation portion of the desired speed and turns into a signal $V_{C}$ applied to the input of the closed speed loop of control system. 


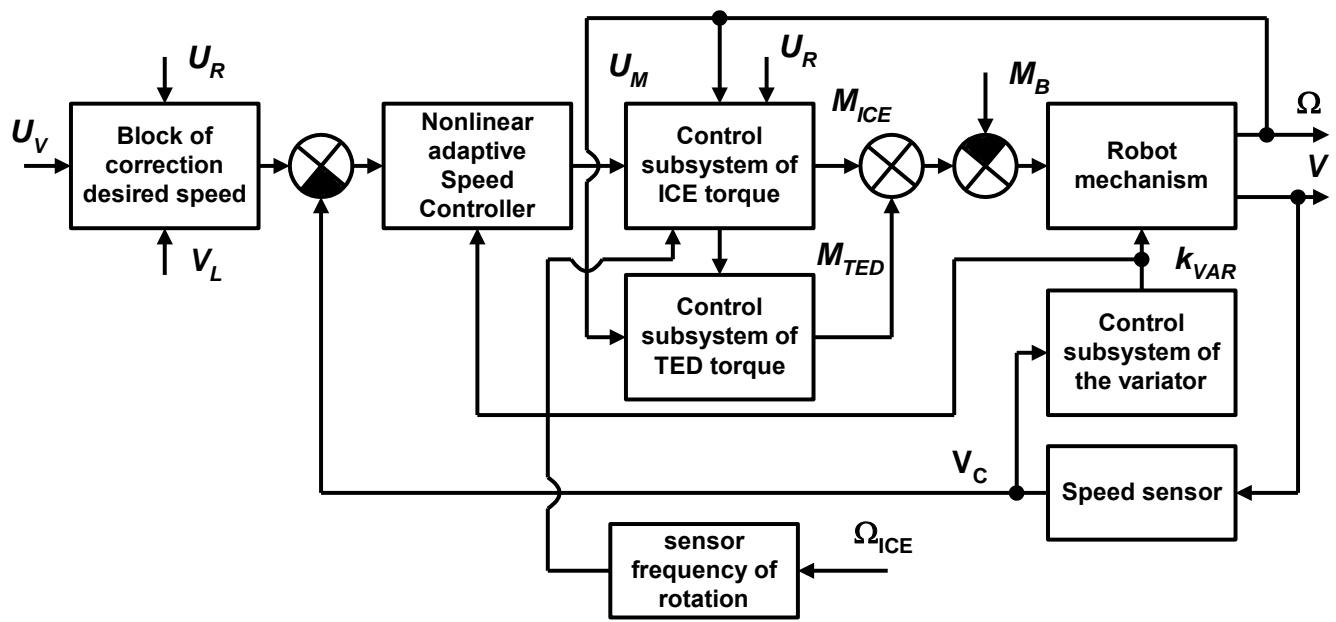

Fig. 2. The structure of the robot control system with hybrid drive

In order to improve the accuracy of the implementation of the desired speed in the main control loop we introduced non-linear adaptive speed control, built on the basis of PI-controller. The values of its adjustable parameters depend on the current value of the transmission ratio of the variator $k_{V A R}$. The output signal of this regulator $U_{M}$ includes information on a desired torque of the hybrid drive. He comes to the input to the control subsystems torque of the ICE and affect the value of torques $M_{I C E}$ and $M_{T E D}$ produced the engine and TED, respectively. In this case control subsystem of TED torque receives input action generated by converting the signal $U_{M}$ to the control unit torque distribution, located inside the control subsystem of ICE torque. Variable transmission ratio which converts control system the movement of mobile robot to a non-linear system, is one of the causes of control problems. There are a various solutions of this problem. Proposed idea of variator control is as follows. In the appointment $k_{V A R . D}$ we will strive to ensure that, for any admissible value of the speed of movement of the robot $V$ the velocity of ICE $\Omega_{\text {ICE }}$ was close to the optimum value $\Omega_{\text {ICE.OPT }}$ corresponding to the mode of formation of the maximum torque the ICE. In this case, the robot will be the most dynamic. Other things being equal, he will more quickly accelerate. Choice of the permissible torque of the ICE under conditions of in durability this case is not considered.

Variable transmission ratio which converts control system the movement of mobile robot to a non-linear system, is one of the causes of control problems. There are a various solutions of this problem. Proposed idea of variator control is as follows. In the appointment $k_{\text {VAR.D }}$ we will strive to ensure that, for any admissible value of the speed of movement of the robot $V$ the velocity of ICE $\Omega_{I C E}$ was close to the optimum value $\Omega_{I C E . O P T}$ corresponding to the mode of formation of the maximum torque the ICE. In this case, the robot will be the most dynamic. Other things being equal, he will more quickly accelerate. Choice of the permissible torque of the ICE under conditions of in durability this case is not considered.

Thus, when variator is controlled, stabilization principle of chosen nominal velocity of ICE is realized. The calculated value of the variator $k_{V A R . C}$ ratio is computed by the formula

$$
k_{V A R . C}=\Omega_{\text {ICE.OPT }} R_{K}\left(V k_{M T}\right)^{-1},
$$

where $R_{K}$-drive wheel radius. An analysis of the characteristics of the consideration ICE shows that the range of values of the engine velocity $\Omega_{I C E}$, in which the ICE torque differs by a maximum up $20 \%$, is observed in the selection $\Omega_{I C E . O P T}$ $=350 \mathrm{rad} / \mathrm{s}$.

The desired variator ratio $k_{V A R . D}$ is calculated taking into account limitations by the formula

$$
k_{\text {VAR.D }}= \begin{cases}k_{\text {VAR.C }} & \text { when } k_{\text {VAR.MIN }}<k_{\text {VAR.C }}<k_{\text {VAR.MAX }}, \\ k_{\text {VAR.MAX }} & \text { when } k_{\text {VAR.C }} \geq k_{V A R . M A X}, \\ k_{\text {VAR.MIN }} & \text { when } k_{V A R . C} \leq k_{\text {VAR.MIN }},\end{cases}
$$

where $k_{V A R . M A X}$ and $k_{V A R . M I N}$ - the minimum and maximum possible values of the transmission ratio of the variator respectively. 
Speed controller provides the adaptation of the control system to change the variator transmission ratio $k_{V A R}$ and the total moment of inertia $J_{\Sigma}$ of the moving parts of the robot, relation to the shaft engine. The algorithm of the controller is described by the following equations:

$$
\begin{aligned}
& \delta_{V}=V_{C}-V, \\
& \frac{d u_{V P}}{d t}=\delta_{V}, \\
& u_{V}=\left\{\begin{array}{l}
u_{V P}, \quad \text { if }\left|u_{V P}\right| \leq u_{V . M A X}, \\
u_{V . M A X} \operatorname{sign}\left(u_{V P}\right), \text { if }\left|u_{V P}\right|>u_{V . M A X},
\end{array}\right. \\
& k_{P C}=k_{P I 0} k_{V A R} J_{\Sigma}, \\
& U_{M P}=k_{P C}\left(\delta_{V}+k_{I C} u_{V}\right), \\
& U_{M}= \begin{cases}U_{M P}, & \text { if }\left|U_{M P}\right| \leq U_{M . M A X}, \\
U_{M . M A X} \operatorname{sign} U_{M P}, & \text { if }\left|U_{M P}\right|>U_{M . M A X},\end{cases}
\end{aligned}
$$

where $k_{P C}$ - the gain of the proportional component PI-controller of the speed; $k_{P I 0}-$ «basic» gain of the PI-controller; $k_{I C}$ - the gain of the integral component PI-controller; $u_{V . M A X}$ and $U_{M . M A X}$ - levels of limitation signals of speed control;

One of the important challenges facing the control system is to ensure the number of constraints imposed on the variables that characterize the functioning of the processes mobile robot with hybrid drive. First of all, at an acceptable level $V_{A C C}$ the linear speed $V$ the mobile robot should be limited to $V_{A C C}$. Value $V_{A C C}$ comes to the input the considered of the control system from higher rank control system and is determined taking into account road conditions, the presence of obstacles, the road inclination in relation to the horizon and other factors. This is achieved by limiting the input impact $V_{C}$ of the block of correction desired speed. To prevent of proslipping of robot driving wheels when a sudden change in the speed of the control action $V_{C}$ is formed taking into account the desired value of the speed in such a way to limit the acceleration to an acceptable level. In this case the calculation of the impact of the rate $V_{C}$ of change is made in accordance with an algorithm

$$
\frac{d V_{C}}{d t}=\left\{\begin{array}{lr}
k_{a}\left|V_{D}-V_{C}\right| \operatorname{sign}\left(V_{D}-V_{C}\right) & \text { when } k_{a}\left|V_{D}-V_{C}\right|<k_{L I M} k_{V A R}, \\
k_{L I M} k_{V A R} \operatorname{sign}\left(V_{D}-V_{C}\right) & \text { when } k_{a}\left|V_{D}-V_{C}\right| \geq k_{L I M} k_{V A R},
\end{array}\right.
$$

where $k_{a}$ and $k_{L I M}$ - proportionality factors affecting the rate of change of the control action outside the limitation and action limitation, respectively.

At the second, to prevent of proslipping (slipping wheels) it should be limited to the total torque $M_{\Sigma}$ produced by the hybrid drive in relation to the rotation axis of driving wheels. This operation is performed in the module limitation the total torque, which is part of the adaptive speed controller. At rise or descent maximum value $M_{\Sigma . M A X}$ of total torque $M_{\Sigma}$ of hybrid drive should be chosen from the condition.

$$
M_{\Sigma . M A X} \leq F_{F F . M A X} R_{W}
$$

where $F_{F F . M A X}-$ the maximum value of the friction force on the of driving wheels of the road surface. This friction force is calculated according to the formula

$$
F_{F F . M A X}=k_{F F} m g\left(\frac{1}{2} \cos \alpha-\frac{L}{B} \sin \alpha\right),
$$

where $k_{F F}$ - the coefficient of static friction between the drive wheels to the road surface; $m$ - robot weight; $g$ acceleration of gravity; $L$ - the distance between the axes of the front and rear wheels of the robot; $B-$ the height of the robot's center of gravity relative to the road surface; $\alpha$ - angle of inclination of the surface (road) relative to horizontal surface, относительно горизонтальной плоскости, a positive value is counted counter-clockwise.

The resulting torque, which leads to move the robot, is determined by the formula 


$$
M_{\Sigma}=M_{\Sigma}-M_{W}
$$

where $M_{W}-$ torque due to the influence of the weight of the robot, and

$$
M_{W}=R_{W} m_{R O B} g \sin \alpha .
$$

Limitations resulting torque of the hybrid drive and the speed movement of mobile robot become important in the energy recuperation mode. In this case, the rules of torque correction and the desired speed correction determined by the command $U_{R}$ generated by mobile robot controller.

\section{Torque control of hybrid drive}

The task of control torque of hybrid drive is subordinated to the task controlling the speed of the mobile robot. The output signal $U_{M}$ of speed controller, containing information about the desired torque of the hybrid drive is divided into two components $U_{I C E}$ and $U_{T E D}$ in the distributor of torque (fig. 3). The component $U_{T E D}$ comes to input of the TED and leads to the formation torque $M_{T E D}$ of the TED. The second component $U_{I C E}$ is worked by control system of ICE torque and formed the torque $M_{I C E}$. The sum of $M_{I C E}$ and $M_{T E D}$ forms the hybrid drive resultant torque $U_{\Sigma}$ and allows the mobile robot to move.

Control subsystem of ICE torque constructed as automatic control system, closed loop by torque the internal combustion engine indirectly measured. Control loop of ICE torque consists of the ICE torque controller, limiter of control action, the control device of ICE, sensor control action, the ICE torque calculator. Required to regulation evaluation of ICE torque is based mathematical model of the ICE on the above and the angular velocity $\Omega_{B}$ measured by the sensor of frequency rotation. Subsystem of ICE torque control attaches astatic property to improve the accuracy of control $M_{T E D}$. For this purpose in the control loop an integrated controller is proposed to use.

The results of theoretical analysis and computer simulations have shown that, to ensure the stability of the ICE control processes it required limiter control action $h$ at the level $h_{L I M}$ depends on the velocity of the ICE crankshaft. It is found that it is possible to take $h_{L I M}=k_{h \Omega} \Omega_{I C E}$, where $k_{h \Omega}=1,45 \cdot 10^{-3}$.

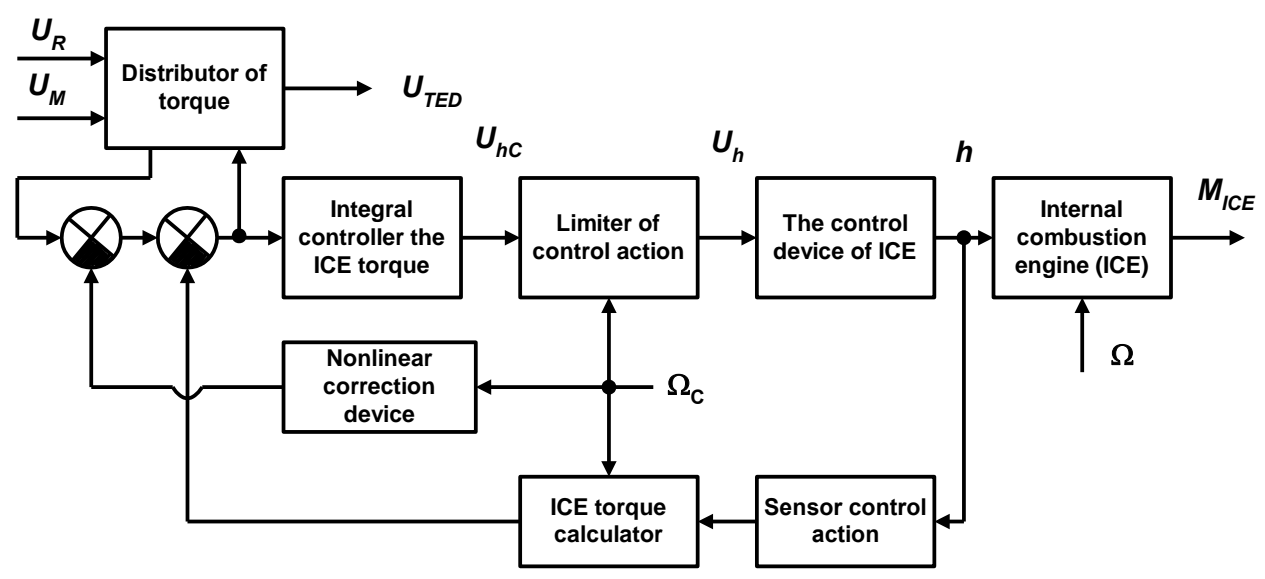

Fig.3 The structure of control subsystem of ICE torque

Additionally, the results indicate advisability of introducing a non-linear correction of the angular velocity of the crankshaft rotation. The dependence $\Omega_{B}$ on the correction signal $U_{\text {KORR }}$ generated by the nonlinear correction device in the form of a link with the dead zone, which has the threshold value of the angular velocity $\Omega_{B 0}$ and the corrective feedback factor $k_{\text {KORR }}$.

One of the problems of control hybrid drive torque is to determine the rule of rational distribution of the desired torque between the ICE and the TED. It is proposed to carry out such distribution, depending on the mode of the hybrid drive of mobile robot. For this purpose the robot control system $U_{R}$ generates a command that comes to distributor of torque. We will distinguish between normal mode $\left(U_{R}=0\right)$ and energy recuperation mode $\left(U_{R}=1\right)$.

In normal mode, it implements the principle of the priority of the ICE. Distributor of torque passes signal, equal to $U_{I C E}$, to input of control subsystem of ICE torque, that corresponding to the desired torque $U_{\Sigma . D}$ of the hybrid drive. 
As a result, ICE seeks to produce all the necessary torque of the hybrid drive. At the input of the TED signal transmitted, which proportional of the error of control subsystem of ICE torque and calculated in the distributor of torque in accordance with the equation

$$
M_{T E D . D}=k_{T E D}\left(M_{\Sigma . D}-M_{I C E}\right),
$$

where $k_{T E D}$ - the coefficient of proportionality.

Thus, in the normal mode the TED plays a subordinate role and serves to increase the total torque of the hybrid drive in those situations, when the ICE alone can't cope with the task. For example, this situation can occur if the ICE doesn't produce enough torque for acceleration or with extremely intensive robot moving on the rise. The TED is a highly dynamic system and effectively manages with the task of rapid formation of an additional component of the total torque of the hybrid drive, providing high values of acceleration and deceleration during the robot motion.

In the energy recuperation mode desired torque $U_{\Sigma . D}$ is divided into two parts $M_{\text {ICE.D }}$ and $M_{T E D . D}$ which are defined by the following rules:

$$
\begin{aligned}
& M_{I C E . D}=k_{I C E . R} M_{\Sigma . D}, \\
& M_{T E D . D}=k_{T E D . R} M_{\Sigma . D} .
\end{aligned}
$$

Moreover, the coefficients $k_{I C E . R}$ and $k_{T E D . R}$ the distribution rule satisfy $k_{I C E . R}+k_{T E D . R}=1$. The following values of these coefficients can be recommended on the basis of the research results: $k_{I C E . R}=0,5 ; k_{T E D . R}=0,5$.

\section{Features of the mobile robot control in the energy recuperation mode}

Transformation mechanical energy into electrical energy and replenish the accumulator is possible only in modes, when the robot commits on descent or moves along the horizontal surface by the ICE. In this case electric motor, in which current is regulated using the PWM, acts as brake and its torque counteracts external torque or ICE torque [5]. Average for the PWM period current $I_{A}$,flowing through the accumulator, can be found by the formula

$$
I_{A}=\frac{k_{E}}{k_{M} U} M_{T E D}\left(M_{T E D} \frac{R_{A}}{k_{M} k_{E}}+\Omega_{I C E}\right)
$$

where $k_{M}$ and $k_{E}$ - torque and speed coefficients of the motor, respectively, $R_{A}$ - resistance circuit consisting of the motor circuit, a frequency converter and accumulator; $U$ - voltage of electric drive. Energy recuperation occurs when $I_{A}<0$. During $0<t<\gamma T_{P W M}$ from the beginning of PWM period under the influence of self-induction EMF current flows into the accumulator. Then, after switching transistor pairs for the time $\gamma T_{P W M}<t<(1-\gamma) T_{P W M}$ current is consumed by accumulator and passes through another pair of transistors, which in this period of time are translated into a state of saturation. When robot moves down the slope energy recuperation is possible if speed $V$ is larger than a certain minimum value $V_{\min }$ :

$$
V>V_{\min }=k_{T E D . R} \frac{R_{A} R^{2}}{\left(k_{M T} k_{V A R}\right)^{2} k_{M} k_{E}} m g \sin \alpha
$$

In this case current of charge $I_{A}$ must be limited to an acceptable level $I_{A \cdot M A X}$. Otherwise, accumulator is overheating, the electrolyte begins to boil and the accumulator can be damaged. Therefore, the robot movement speed should be limited to the top

$$
V \leq V_{\min }+\Delta V
$$

besides

$$
\Delta V=\frac{I_{A . M A X} k_{M} U}{k_{T E D . R} k_{E} m g \sin (\alpha+\Delta \alpha)}
$$

where $\Delta \alpha-$ small auxiliary quantity, preventing division by zero at movement on the horizontal segment of the path. 
Accumulator charge increases with speed of movement increase. Therefore, in the energy recovery mode advantageously selected speed equal to

$$
V_{M A X}=V_{\min }+\Delta V
$$

On the other hand, the desired speed $V_{D}$ of robot motion must be less than allowed speed $V_{A C C}$, which is determined by taking into account the angle of inclination of the surface and other characteristics of the track. The correction is made in the block correction of desired speed. To fill the accumulator when the robot moves in the horizontal section of the trajectory, the control system of hybrid drive changes the TED to the braking mode. The TED produces the braking torque $M_{T E D}$. In this case mechanical energy produced by the ICE is converted into electrical energy. Torque $M_{T E D}$ selected from the condition of existence of the recuperation process

$$
0>M_{T E D}>-\Omega_{I C E} k_{M} k_{E} R_{A}^{-1}
$$

taking into account the speed of robot movement and the necessity limit the accumulator current to the formula

$$
M_{T E D}=-b-\sqrt{b^{2}+\frac{I_{A \cdot M A X} k_{M}^{2} U}{R_{A}}},
$$

where

$$
b=-V \frac{k_{M T} k_{V A R} k_{M} k_{E}}{2 R R_{A}}
$$

\section{The results of computer modeling control processes of speed mobile robot with hybrid drive}

In order to determine the main features of the functioning of the mobile robot with the proposed structures and algorithms of control systems, we have carried out computer modeling of its movement in the horizontal section of the track, on the ascent and the descent. In this case we can determine the character of the change speed of robot movement, torque of the hybrid drive and the current accumulator charge in the energy recuperation. We consider the robot with the following values: robot weight is $1000 \mathrm{~kg} ; R_{W}=0,3 \mathrm{~m} ; k_{M T}=4 ; k_{V A R}=1 \ldots 4 ; J_{W}=0,225 \mathrm{~kg}^{*} \mathrm{~m}^{2} ; J_{T P H}=0,1 \mathrm{~kg} * \mathrm{~m}^{2}$; $J_{R T}=0,66 \mathrm{~kg}^{*} \mathrm{~m}^{2} ; B=0,6 \mathrm{~m} ; L=3 \mathrm{~m} ; k_{F F}=0,5 ; T_{V A R}=0,05 \mathrm{sec}, T_{Y y}=0,02 \mathrm{sec}$. Electric motor in the TED has following parameters: nominal torque is $50 \mathrm{Nm}$; nominal angular velocity is $600 \mathrm{rad} / \mathrm{sec} ; U=250 \mathrm{~V} ; k_{M}=0,333 \mathrm{Nm} / \mathrm{A}$; $k_{E}=0,333 \mathrm{V*sec} /$ рад; $R_{A}=0,333 \mathrm{Ohm} ; \omega_{C T}=330 \mathrm{sec}^{-1}$.

"Basic" of the speed controller gain $k_{P I 0}$ is assumed to be 200 , and the gain the integral component $k_{I S}=5 \mathrm{sec}^{-1}$. Gain factors of integral controller of the ICE and the TED have the same values, equal to $30 \mathrm{sec}^{-1}$. Maximum accumulator current of charge is $I_{A . M A X}=10 \mathrm{~A}$. Fig. 5-10 shows the results of computer simulation of mobile robot operation during acceleration. Movement of the robot begins on the horizontal section, and after a time equal to 20 seconds, starts the rise on angle 10 degrees. The process of changing speed movement of the robot during acceleration from speed $2 \mathrm{~m} / \mathrm{sec}$ up to $5 \mathrm{~m} / \mathrm{sec}$ is shown in Fig. 4. The process of forming the resultant torque of the hybrid drive is shown in Fig. 5. In this situation, speed is relatively low. Therefore, the variator ratio is the highest constant value. Robot speed changes smoothly without overshoot and the acceleration process completed in approximately 6 seconds. Robot control system doesn't involve the TED, because the ICE has sufficient capacity to bring the robot to move to the desired rule.

Process robot acceleration from speed $2 \mathrm{~m} / \mathrm{sec}$ to a speed of $10 \mathrm{~m} / \mathrm{sec}$ looks somewhat different (fig. 6). It can be seen that the acceleration is more intense and there is a small oscillation in the final stage. The higher intensity of acceleration is due to the automatic adjustment of the variator ratio. With the speed of increasing value $k_{V A R}$ is reduced if the speed increases more rapidly. The process of changing torque of the hybrid drive is shown in Fig. 7. Same as in the previous experiment, it is completely ensured by the ICE.

The process of increase speed during acceleration $2 \mathrm{~m} / \mathrm{sec}$ to $25 \mathrm{~m} / \mathrm{sec}$ is shown in Fig. 8. Obviously, the duration of the process of speed control is greater than in the previous cases, because a considerable range of speed changes is set and the torque limit of the drive is shown. Clearly it expressed "zonality" of the process. At a small robot speed the variator ratio is great, then it decreases rapidly and reaches a minimum value by the end of the process. Reducing the value $k_{V A R}$ leads to an increase equivalent coefficient in the transmission of the executive part of the system. Stabilization of dynamic features of control system is provided by adaptive speed controller. 


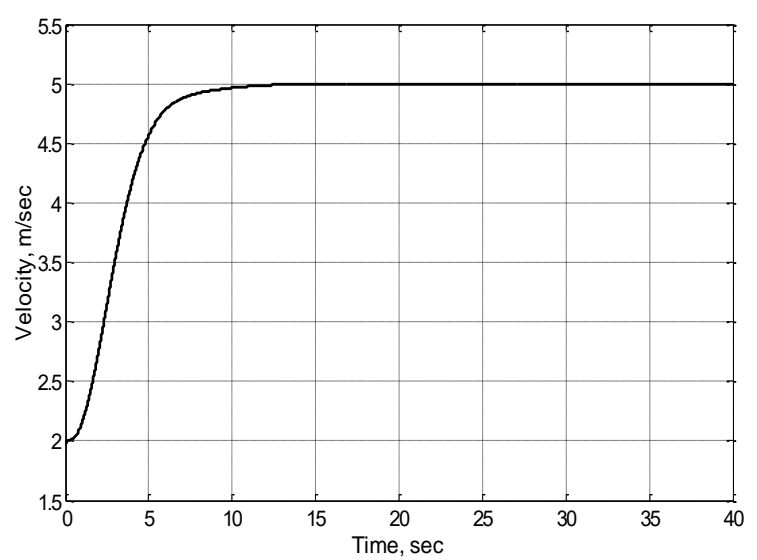

Fig. 4 Graph of speed changes during acceleration from $2 \mathrm{~m} / \mathrm{sec}$ to $5 \mathrm{~m} / \mathrm{sec}$

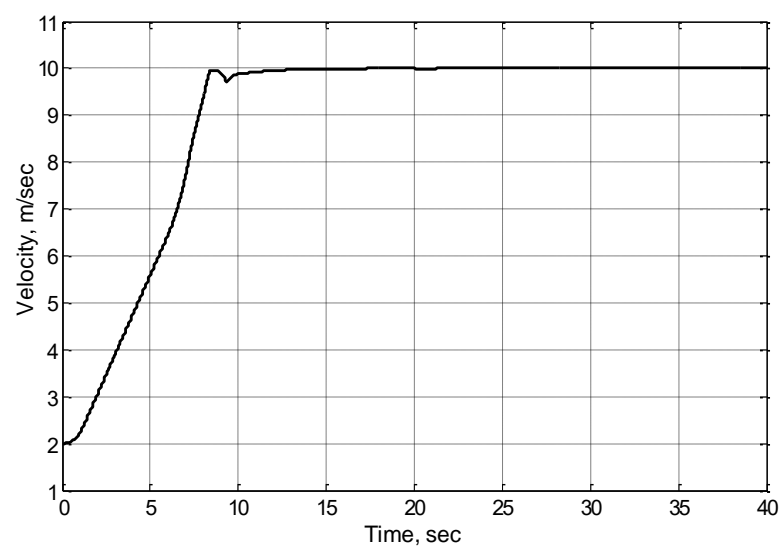

Fig. 6 Graph of robot speed changes during acceleration from $2 \mathrm{~m} / \mathrm{sec}$ to $10 \mathrm{~m} / \mathrm{sec}$

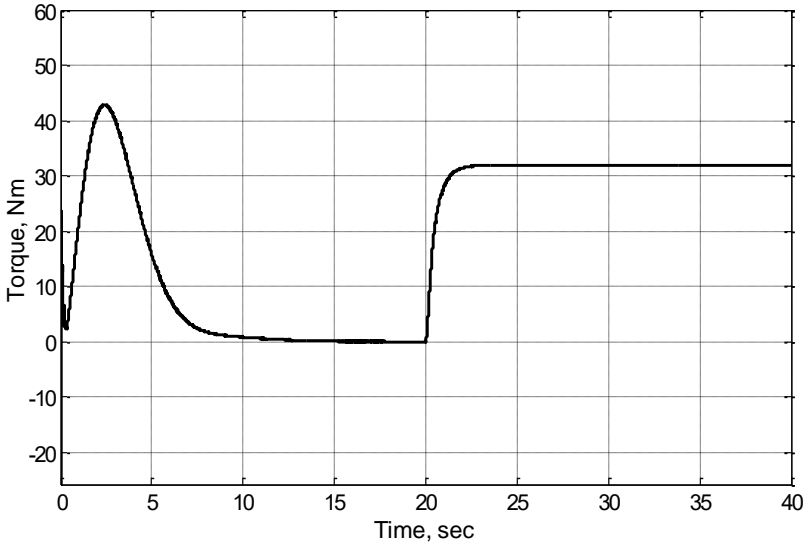

Fig. 5 Graph of torque changes of hybrid drive during acceleration from $2 \mathrm{~m} / \mathrm{sec}$ to $5 \mathrm{~m} / \mathrm{sec}$

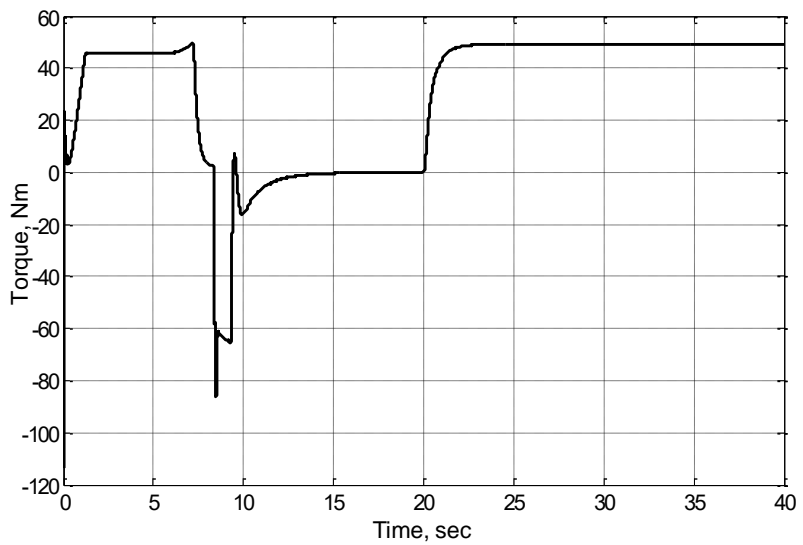

Fig. 7 Graph of torque changes of hybrid drive during acceleration from $2 \mathrm{~m} / \mathrm{sec}$ to $10 \mathrm{~m} / \mathrm{sec}$

The resulting torque of the hybrid drive is also undergoing significant changes (fig. 9). Phases of acceleration and deceleration are observed, when the torque is negative. Negative torque is provided mainly by TED, having a quick performance. The final value of torque is substantially greater than the initial, because robot climbs up the hill, and the value $k_{V A R}$ is minimal.

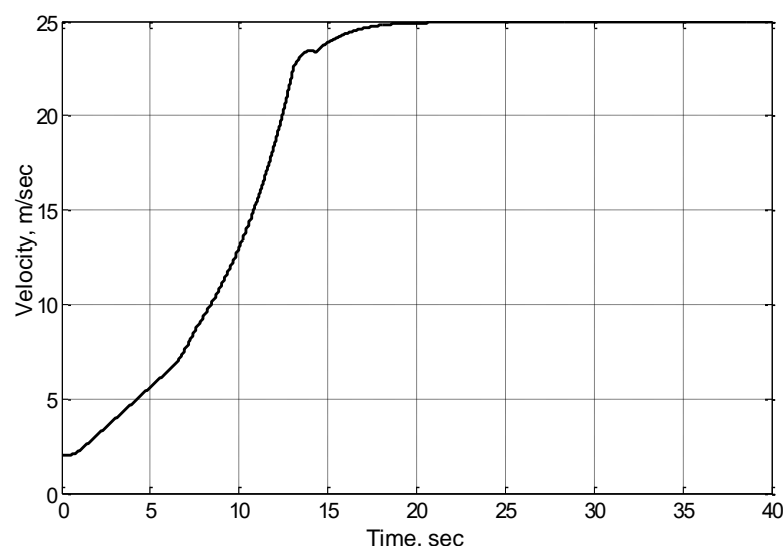

Fig. 8 Graph of robot speed changes during acceleration from $2 \mathrm{~m} / \mathrm{sec}$ to $25 \mathrm{~m} / \mathrm{sec}$

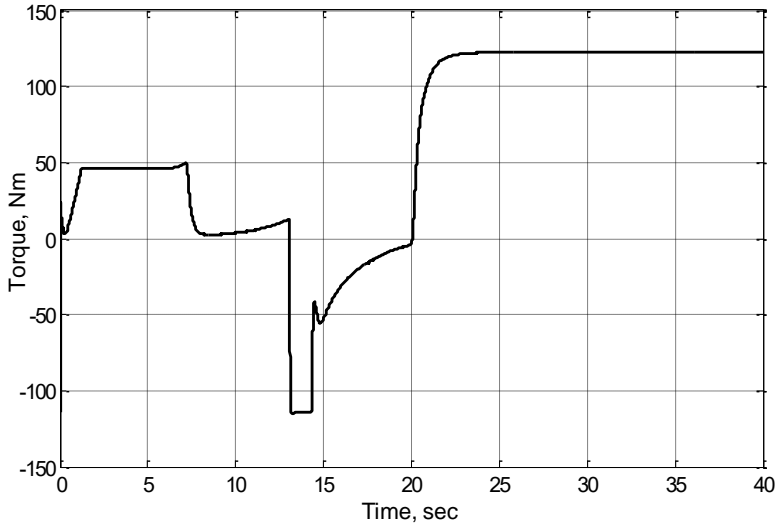

Fig. 9. Graph of torque changes of hybrid drive on descent and acceleration from $2 \mathrm{~m} / \mathrm{sec}$ to $10 \mathrm{~m} / \mathrm{sec}$

The simulation results describing movement of the robot during the descent, are shown in Fig. 10-11. The process begins on the horizontal section, and at time equal 20 seconds, the descent takes place at an angle of -10 degrees. The process of changing the speed of robot movement during its acceleration from speed $2 \mathrm{~m} / \mathrm{sec}$ up to a speed $10 \mathrm{~m} / \mathrm{sec}$ is shown in Fig. 10. In this case control system automatically adjusts the speed of movement taking into account the inclination angle, reducing it to a safe level by the TED, which works as a brake. Thus, there is the current change in the 
TED (fig. 11). As the result of braking energy recuperation process provides accumulator charging. After the transient processes current reaches the desired level of security equal -10A.

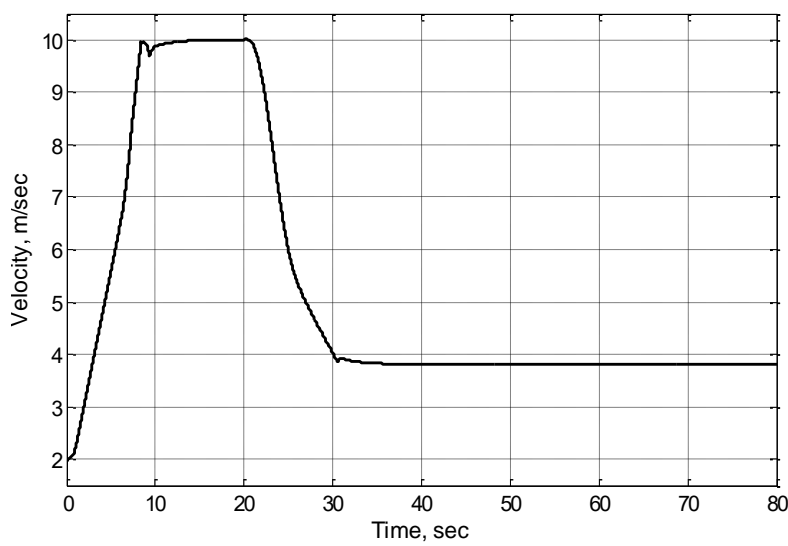

Fig. 10 Graph of robot speed changes on descent and acceleration from $2 \mathrm{~m} / \mathrm{sec}$ to $10 \mathrm{~m} / \mathrm{sec}$

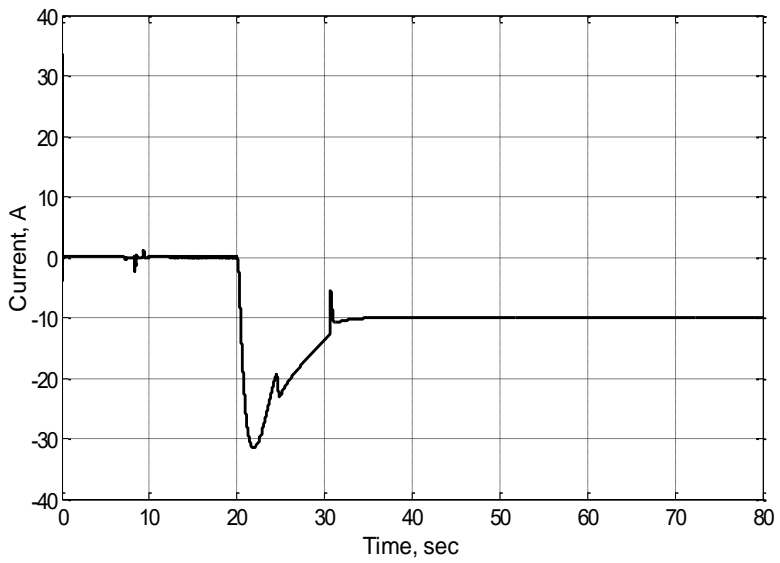

Fig. 11 The process of charging accumulator current when the robot moves on descent

Fig. 12 shows the process of changing the speed of movement of the robot moving the horizontal part of the track. This process begins with acceleration from speed $2 \mathrm{~m} / \mathrm{sec}$ to speed of $15 \mathrm{~m} / \mathrm{sec}$. It is starting at time equal to $20 \mathrm{sec}$, it is converted into an energy recuperation mode. The TED produces a torque of resistance to movement of the robot. The electric motor mainly operates as a generator and the accumulator charge occurs (fig.13).

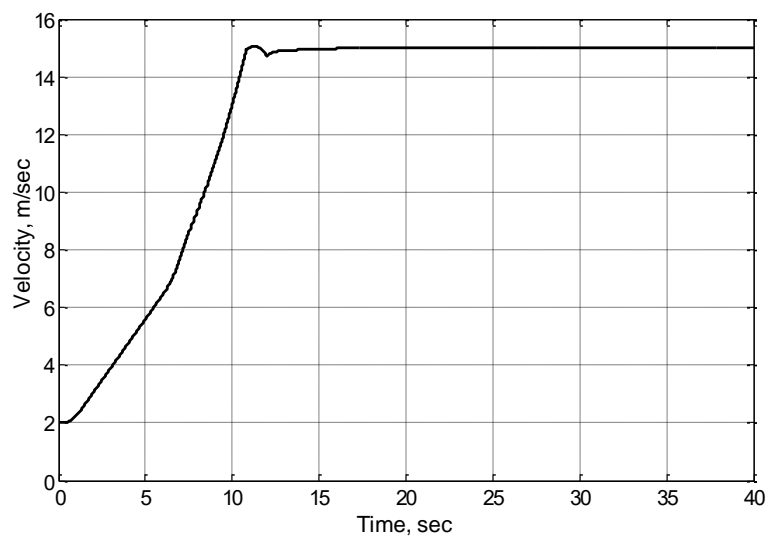

Fig. 12 Graph of robot speed changes on the horizontal section of the path and acceleration from $2 \mathrm{~m} / \mathrm{sec}$ to 15 $\mathrm{m} / \mathrm{sec}$

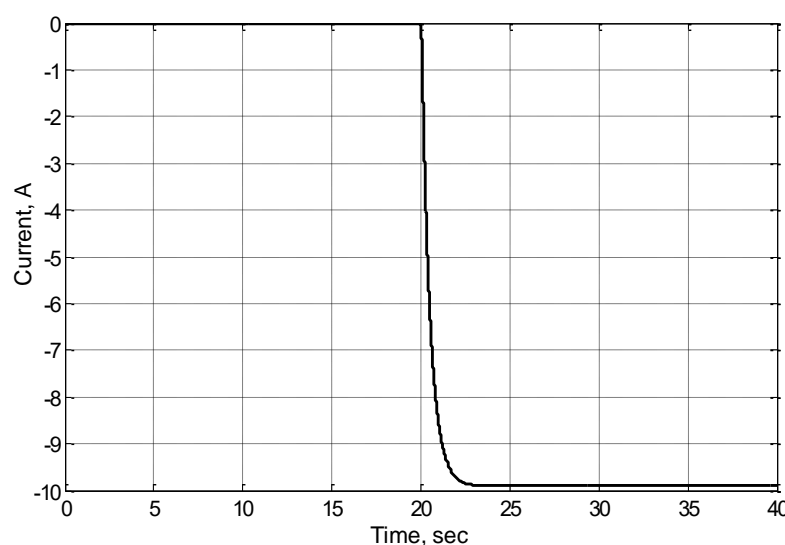

Fig.13 The process of accumulator current control in the recuperation mode, when the robot is moving along the horizontal section

As it follows from Fig. 13, the control system limits the charging current to an acceptable level equal to -10 A.

\section{Conclusion}

The paper presents solution to the problem of the control movement of mobile robot with a hybrid drive. This problem was solved by analyzing the characteristics of the components that form the hybrid drive, this required the development of new structures and motion control algorithms for robots with such drives. First of all, it should be noted that we obtained a closed system of automatic speed robot motion control with subordinate control subsystem torque of the hybrid drive. In its turn this subsystem consists of two interacting elements that ensure regulation of torques of the ICE and the TED. It was found reasonable to use the adaptive speed controller. It allowed stabilize the dynamic properties of the robot when changing the transmission ratio. The peculiarity of the proposed solutions is also related to the need to introduce a series of non-linear elements in the control of the system. We proposed to use the distributor of torque and block of correction of the desired speed. It is crucial that both the control system components have varying structures and their operation algorithms depend on the selected operating mode.

We solved the problems of definition robot structure with the considered type of drive, the formation of its mathematical model, the development of rules and automatic control algorithms in different driving modes, including taking into account energy recuperation processes. The given results of theoretical studies and computer simulations have 
confirmed the effectiveness of the proposed solutions. The author's future plans will be aimed at improving control algorithms of robot with hybrid drives, solving questions planning trajectories and profiles of speeds of movement these robots on a given route.

\section{Acknowledgments}

The present paper was carried out under the financial assistance of the Ministry of Education and Science of the Russian Federation in the framework of the state assignment in the field of scientific activities (assignment № 2014/105, project № 1678).

\section{References}

[1] Mailah A. H. Ali, M., Tang H. H., Rahim M. A. A., "Autonomous Mobile Robot Platform for On-the-Road Navigation", Advanced Materials Research, Vol. 845, pp. 750-754, 2014

[2] Katsurin, A[lexey] (2016). Planning Trajectory of the Mobile Robot with a Camera, Proceedings of the 26th DAAAM International Symposium, pp.0407-0416, B. Katalinic (Ed.), Published by DAAAM International, ISBN 978-3-902734-07-5, ISSN 1726-9679, Vienna, Austria

[3] Ionescu, G. \& Boiangiu, C. A.: Mobile Platform for Environment Analysis, Annals of DAAAM for 2012 \& Proceedings of the 23rd International DAAAM Symposium, ISBN 978-3-901509-91-9, ISSN 2304-1382, pp 0587 - 0590, Editor B[ranko] Katalinic, Published by DAAAM International, Vienna, Austria, 2012.

[4] Andreev V.P., Pryanichnikov V.E. Operation Environment of Mobile Robots with Supervision Control, Annals of DAAAM for 2011 \& Proceedings of the 22nd International DAAAM Symposium, Volume 22, No. 1, Vienna, Austria, 2011, pp. 0021-0022.

[5] Ilyukhin Y.V., Tatarintseva A.V. Strategy motion control of mobile robots with hybrid drives according to energy recuperation. //Advanced Materials Research Vols.1079-1080 pp895-898 (2015) Trans Tech Publications, Switzerland (2015)

[6] Sun Y. T., Zhang J. Z., Wang Y. L., Fan D. H., Zhu R. F., "Analysis of Typical Driving Condition Test and Control Strategies Based on Toyota Prius", Advanced Materials Research, Vol. 977, pp. 321-325, 2014

[7] Sun Y. T., Zhang H. T., Wang Y. L., "Toyota Prius Control Strategy Experiment Analysis", Advanced Materials Research, Vols. 591-593, pp. 1762-1765, 2012

[8] I. F. Fileru, "Toyota Prius - A Successful Pioneering in Hybrid Vehicle World", Applied Mechanics and Materials, Vols. 809-810, pp. 1139-1144, 2015

[9] Liu Z. T., He H. W., Li W. Q., "Optimization of Economy Shift Schedule for Automated Mechanical Transmission in a Parallel Hybrid Electric Vehicle", Applied Mechanics and Materials, Vols. 260-261, pp. 331-336, 2013

[10] Damic V., Cohodar M., Kulenovic M. Physical modeling and simulation of mechatronics systems by acausal bond graphs. Annals of DAAAM for 2011 \& Proceedings of the 22nd International DAAAM Symposium, Volume 22, No. 1, ISSN 1726-9679, ISBN 978-3-901509-83-4, Editor B. Katalinic, Published by DAAAM International, Vienna, Austria, EU, 2011

[11] Ilyukhin Yu.V., Computer control of mechatronic systems., MSTU "STANKIN", Moscow, 2014.

[12] Ilyukhin Yu.V., Poduraev Yu.V., Tatarintseva A.V., Nonlinear Adaptive Correction of Continuous Path Speed of the Tool for High Efficiency Robotic Machining. Volume 100, 2015, Pages 994-1002. (25th DAAAM International Symposium on Intelligent Manufacturing and Automation, 2014)

[13] Ilyukhin Yu.V, Tatarintseva A.V., Mathematical model and features of the mobile robot control with mechatronic hybrid. Journal of the Samara State Aerospace University named after Academician S. Korolev (National Research University) №2 (33). Samara, p. 222-227, 2012

[14] Witwit A. R. H., Yasin A., Gitano H., Yadav T. K., "New Model for Knock Factors Optimization in Internal Combustion Engine (SI)", Advanced Materials Research, Vol. 980, pp. 219-224, 2014

[15] Niu Q. Y., Fan C., Wang X. C., Zhao Y. W., Dong Y. C., "Research on the Parameter Calibration of the InternalCombustion Engine Work Process Simulation Model", Advanced Materials Research, Vols. 308-310, pp. 953-961, 2011

[16] http://www.zmz.ru/files/PP40524(02).pdf The internal combustion engine ZMZ-40524.10. Instructions for use, maintenance and repair. OAO «Zavolzhsky Engine Plant», 2008. 